\title{
Aches and Pain in a child- An unusual cause
}

\author{
Latha Magatha Sneha ${ }^{1}$, Abhinayaa J², Kannan Karthik Kailash ${ }^{3}$, Julius Xavier Scott ${ }^{4}$
}

${ }^{1}$ Dr. Latha Magatha Sneha, Assistant Professor of Pediatrics, MD Pediatrics, Division of Pediatric Hemato Oncology, ${ }^{2}$ Dr, Abhinayaa J, $2^{\text {nd }}$ year Postgraduate, MD Pediatrics, Division of Pediatric Hemato Oncology, ${ }^{3}$ Dr Kannan Karthik Kailash MBBS, D Ortho, MCh Ortho, Fellow Spine Surgery UK \& USA, Head, Division of Spine Surgery, ${ }^{4}$ Dr Julius Xavier Scott, MD DCh DNB, Fellowship in Pediatric, Hemato Oncology- Australia, Professor of Pediarics and Head, Division of Pediatric, Hemato Oncology, Sri Ramachandra University, No.1, Ramachandra Nagar, Porur, Chennai600116, TamilNadu, India.

Address for Correspondence: Dr Julius Xavier Scott, Email:jxscott@hotmail.com

\begin{abstract}
Precursor B-cell lymphoblastic lymphoma presenting with severe pain and extensive skeletal lesions as an initial presentation is very rare. We report a nine year old boy who presented with lower backache and difficulty in walking of 2 months duration. He neither had lymphadenopathy nor organomegaly. His peripheral blood picture and bone marrow examination were normal. MRI revealed multiple lytic lesions in the spine and PET scan revealed metabolically active lytic lesions in the axial skeletal system and bilateral femurs and humerus. Biopsy of the vertebra revealed the diagnosis of precursor B cell lymphoma. A diagnosis of malignancy should never be missed in a patient with musculoskeletal pain, having ruled out infectious and traumatic etiologies especially when they present with several skeletal radiolucencies.
\end{abstract}

Keywords- Precursor B cell Lymphoma, Extensive skeletal lesions, Children, Pain

\section{Introduction}

Precursor B-cell lymphoblastic lymphoma is rare and constitutes less than $10 \%$ of the lymphoblastic lymphoma cases [1]. B cell lymphoblastic lymphomahas been well known to involve extranodal sites. Skin, bone and soft tissue are few common sites of occurrences. Mediastinal involvement has been found to be rare unlike $\mathrm{T}$ cell Lymphoblastic Lymphoma. The second most common site of extranodal presentation is bone, with skin being the most common [2].

\section{Case Report}

A 9 year old boy presented with lower backache and generalized pain causing difficulty in walking of 2 months duration. He had history of trivial fall over back 10 days prior to onset of symptoms. On presentation he had no pallor, icterus, hemorrhagic manifestations, significant lymphadenopathy or hepatosplenomegaly. He had generalized pain with tenderness over the spine, left elbow and dorsum of foot.

His investigations revealed hemoglobin of $10 \mathrm{~g} / \mathrm{dl}$, white blood cell count of $8500 \mathrm{cells} / \mathrm{cu} \mathrm{mm}$, platelets of $2.931 \mathrm{lakhs} / \mathrm{cu}$ $\mathrm{mm}$. Peripheral smear examination revealed microcytic, hypochromic RBCs, anisopoikilocytosis with no blasts. His renal and liver function tests were normal. Serum uric acid level was $4.4 \mathrm{mg} / \mathrm{dl}$ and lactate dehydrogenase was $266 \mathrm{U} / \mathrm{L}$. Urinary vanillylmandelic acid level was normal. X-ray spine done did not reveal any significant changes. MRI spine revealed

Manuscript received: $14^{\text {th }}$ January 2017

Reviewed: $20^{\text {th }}$ January 2017

Author Corrected: $28^{\text {th }}$ January 2017

Accepted for Publication: $9^{\text {th }}$ February 2017 
multiple osteolytic lesions in D9 and D11 vertebra (Fig 1). Bone marrow aspiration revealed occasional blast cells but was not conclusive. Biopsy of D9 vertebra done revealed small blue cell tumour but was inconclusive of any type of malignancy.

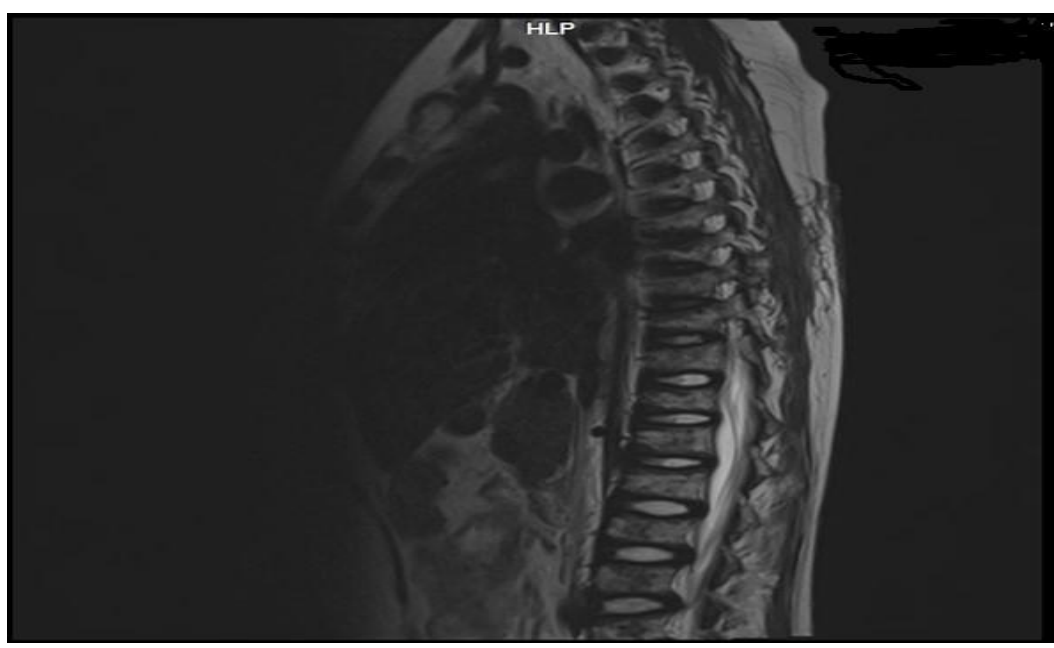

Fig-1: Magnetic resonance imaging showing multiple lytic lesions throughout the spine

PET scan revealed diffuse metabolically active lytic lesions in axial skeletal system and bilateral humerus and femurs, few metabolically active non-calcific bilateral cervical, axillary, pectoral and upper precaval lymph nodes with diffuse increased metabolic activity in enlarged spleen.

Repeat biopsy of D9, D11 vertebra done showed high grade small blue round cell tumour. On Immunohistochemistry, tumour cells were positive for Leukocyte common antigen, CD79a, CD10, Terminal Deoxynucleotidyl Transferase and BCL2 while being negative for CD20 and CD3 suggestive of Lymphoblastic Lymphoma- B cell phenotype. Parents were counseled in detail about the disease and patient was started on treatment as per Acute Lymphoblastic Leukemia Children's Oncology Group (COG) protocol. Pain subsided within 2 weeks of treatment and he is currently going to school with no restriction of daily activities.

He is currently in the maintenance phase of chemotherapy, clinically without any pain and well, going to school regularly.

\section{Discussion}

Precursor B cell Lymphoblastic Lymphoma is rare in children and can cause a diagnostic dilemma in view of its variable presentation. There are only few cases presenting with bone involvement as an initial presentation of B cell Lymphoblastic Lymphoma published in literature so far in pediatric age group [2].

Lymphoblastic lymphoma cells and lymphoblasts of acute lymphoblastic leukemia (ALL) are almost impossible to distinguish.

To distinguish Lymphoblastic Lymphoma from ALL, the criteria are:

- Manifestation as bulky masses in solid organs

- Focal $(<25 \%)$ or absent bone marrow involvement

- Absence of peripheral blood involvement [3]
B cell Lymphoblastic Lymphoma must be also differentiated from small round blue cell tumour such as Ewing's Sarcoma, diffuse large B-Cell lymphoma, T cell Lymphoblastic Lymphoma and acute Myelogenous Leukemia. B-cell lymphoblastic lymphoma has been known to have multiple sites of bone involvement like femur, tibia, humerus, vertebrae, scapula, foot and rib [4]. Our patient had lesions in the vertebra, femur, foot and humerus.

Bone pain mimicking inflammatory lesion, gait disturbances, vertebral body collapse and related symptoms are its clinical manifestations [4]. Radiologically, they can present as lytic and/or sclerotic lesions, diffuse osteopenia, periosteal new bone formation and metaphyseal bands [4]. The findings are 
not specific and must be distinguished from other conditions affecting the bone like Ewing's Sarcoma. Sclerosis as an initial presentation can be seen in 47$69 \%$ of the cases [5]. In a study done in B-cell lymphoblastic lymphoma patients, $92 \%$ had no evidence of bone marrow disease at the time of diagnosis [2]. Osteolytic lesions are commonly associated with hypercalcemia. A likely cause for extensive osteolytic lesions and hypercalcemia in these patients is Parathormone- related protein (PTHrP) produced by lymphoblast [6]. Hypercalcemia was absent in our patient even though he presented with extensive osteolytic lesions.

On immunophenotyping, positive stains for B-cell lymphoblastic lymphoma are CD-19, cytoplasmic CD79a, tdt, HLA-DR, CD10 and are found to be positive in most cases [4].

11q 23 translocation, $\mathrm{t}(9 ; 22), \mathrm{t}(12 ; 21)$ are few molecular abnormalities known to have correlation with B-cell lymphoblastic lymphoma [4]. Short intensive chemotherapy and Acute Lymphoblastic Leukemia (ALL) like chemotherapy can be used to treat B cell Lymphoblastic Lymphoma but prognosis has been better with ALL like chemotherapy [7].

B cell lymphoblastic lymphoma has been found to have better outcomes compared to $\mathrm{T}$ cell lymphoblastic lymphoma. The presence of $\mathrm{t}(9 ; 17)(\mathrm{q} 34 ; 3)$ in children has been found to have a correlation with an aggressiveclinical course but no other molecular or chromosomal abnormalities have shown to have any such prognostic importance [8].

Although a rare disease, patients with precursor B-cell lymphoblastic lymphoma undergo complete remission and have high percentage of survival with appropriate chemotherapy. Hence accurate diagnosis of B cell Lymphoblastic Lymphoma is of prime importance. To conclude, physicians who deal with children with pain should be aware that even in the absence of peripheral blood or bone marrow involvement, in a child with excruciating pain and extensive skeletal lesions should be suspected to have malignancy.
Funding: Nil, Conflict of interest: None initiated, Perission from IRB: Yes

\section{References}

1. Sander CA, Medeiros LJ, Abruzzo L V, Horak ID, Jaffe ES. Lymphoblastic Lymphoma Presenting in Cutaneous Sites. A Clinicopathologic Analysis of Six Cases. J Am Acad Dermatol. 1991; 25:1023-1031.

2. Lin P, Jones D, Dorfman DM, Medeiros LJ. Precursor B-cell lymphoblastic lymphoma: a predominantly extranodal tumor with low propensity for leukemic involvement. Am J Surg Pathol. 2000;24: 1480-90.

3. Murphy S B. Childhood Non-Hodgkin's Lymphoma. N Engl J Med 1978;299:1446-48.

4. Younes S. Bone Hematologic neoplasms Lymphoblastic lymphoma. Pathol. Inc. 2014. Available at: http:// pathologyoutlines. Com /topic/ bonelympho blasticlymphoma. html. last accessed Nov 2015

5. Chell J, Fernandes JA, Bell MJ. The orthopaedic presentation of acute leukaemia in childhood. Ann R Coll Surg Engl. 2001;83:186-9.

6. Shimonodan H, Nagayama J, Nagatoshi Y et al. Acute lymphocytic leukemia in adolescence with multiple osteolytic lesions and hypercalcemia mediated by lymphoblast-producing parathyroid hormone-related peptide: A case report and review of the literature. Pediatr Blood Cancer. 2005;45:333-39.

7. Belgaumi AF, Al-Kofide A, Sabbah R, Shalaby L. Precursor B-cell lymphoblastic lymphoma (PBLL) in children: pattern of presentation and outcome. J Egypt Natl Canc Inst. 2005;17:15-9.

8. Kaneko Y, Shikano T, Maseki N, Sakurai M, Takeda $\mathrm{T}$, Hiyoshi $\mathrm{Y}$ et al. Clinical characteristics of infant acute leukemia with or without 11q23 translocations. Leukemia.1988;2:672-6.

\section{How to cite this article?}

Latha Magatha Sneha, Abhinayaa J, Kannan Karthik Kailash, Julius Xavier Scott.Aches and Pain in a child- An unusual cause. J PediatrRes. 2017; 4(02):188-190.doi:10.17511/ijpr.2017.102.18. 